\title{
Comparing Pre- and Intra-Covid-19 students' perception of the digitalization of higher education institutions
}

\author{
Sven Packmohr' ${ }^{1}$, Henning Brink ${ }^{2}$ \\ ${ }^{1}$ Department of Computer Science and Media Technology, Malmö University, Sweden, \\ ${ }^{2}$ Department of Organization and Information Systems, Osnabrück University, Germany.
}

\begin{abstract}
Higher education institutions (HEIs) are significantly progressing, especially to external affordances caused by Covid-19. Digital assets are an opportunity during the pandemic to secure social distance and enhance the students' learning experience at the same time. Also, student administration might benefit from new digitally-enhanced opportunities. There is no uniform procedure for the use of digital media in teaching and student services. Thus, HEIs need to ascertain students' attitudes toward the technologies used. To compare attitudes before and during the pandemic, we surveyed students about their perceptions. The first round of surveys was completed in a blended learning setting in fall 2019 before the global pandemic of Covid-19. The second round was conducted in an online learning setting in February 2021 after nearly one year of higher education under Covid-19. Our results show that students' perceptions toward digitalization at HEIs differ in many aspects due to the Covid-19 pandemic. Students during the pandemic are more critical of the effects on their learning success. The study indicates that the adoption has taken place more quickly in services. Still, teaching concepts and the learning culture are lagging.
\end{abstract}

Keywords: Higher education; organization; digitalization; learning; technology; Covid-19. 


\section{Introduction}

Pandemic and digitalization are changing our daily lives. Already before the pandemic, teaching and learning at higher education institutions (HEIs) were changed by digital means (Castro, 2019). Student assistance, administration processes, knowledge transfer, and assessment become more digitalized. Digital infrastructure enhances constructive learning approaches, access to learning materials, communication, and cooperation between different interest groups. For many HEIs, digitalization is a trend to follow. Nevertheless, it became imperative during the pandemic. HEIs are having difficulties in adopting technologies (Carver, 2016; Reid, 2014). Now, they are forced to implement them. As different stakeholder groups have very different demands, their complex entanglements hinder the digitalization of the HEIs (Reid, 2014).

This paper contributes to research aiming to explore existing issues in digitalization. From the students' point of view, we survey their perception of their HEI's digitalization before and during Covid-19. Our working hypothesis is that there is a difference in the perception due to the enforced acceleration of digitalization. Thus, our research question is: How differently do students perceive their HEI's digitalization in 2019 and 2021? We examine their perception by employing dimensions such as trust, learning, and organizational culture.

In our study, students experience digitalization as users. As they grew up as digital natives (Crittenden, Biel, \& Lovely, 2019), they are particularly critical of the digitalization of HEIs. Moreover, they will experience the effects of digitalization in their professional careers (Friga, Bettis, \& Sullivan, 2003).

In the next section, we present the theoretical background of our work. After, we introduce our research approach, followed by a description of the results. We close the paper with short conclusions and explain the implications and limitations of our work.

\section{Digitalization of Higher Education Institutions}

Digital technologies in education support lecturers in enriching learning resources and evaluating learning goals (Vogelsang, Droit, \& Liere-Netheler, 2019). Further, digitalized processes accelerate service support. Digital technologies converge teaching and administration. Thus, students' results become more transparent and transferrable. Also, convergence has the potential to lead to more efficient processes. As HEIs operate in a more and more competitive environment, efficiency and competitive advantage become imperative (Adler \& Harzing, 2017). With the ubiquitously digital availability, faculty and administrative staff issues arise (Proserpio \& Gioia, 2007).

Digital assets have been used very heterogeneously in higher education. Now, the pandemic forces HEIs into usage and adoption (Mittal, Mantri, Tandon, \& Dwivedi, 2021). Often, 
research has focused on the evaluation of learning settings (Lapitan, Tiangco, Sumalinog, Sabarillo, \& Diaz, 2021), effects of students' individual learning success (Janson, Söllner, Bitzer, \& Leimeister, 2014), or measurement of systems' acceptance and success (Tselios, Daskalakis, \& Papadopoulou, 2011; Ouajdouni, Chafik, \& Boubker, 2021). Besides drivers and barriers (Gregory \& Lodge, 2015), studies provide suggestions for the didactic design of learning elements (Talley \& Scherer, 2013; Tejedor, Cervi, Pérez-Escoda, Tusa, \& Parola, 2021). A smaller branch of research deals with organizational anchoring and adoption (Porter \& Graham, 2016). Even the pandemic did not trigger strong operational responses in HEIs (Miller, 2021). In HEIs, some resistance to change exists and is a source for issues with organizational integration of digital technologies (Al-Senaidi, Lin, \& Poirot, 2009). Especially, teaching scenarios play a significant role in research in higher education. Thus, generalizations of results are only possible to a limited extent. A generally accepted instrument that addresses challenges and shows solution paths is still lacking.

\section{Research Method and Sample}

To measure the impact of the Covid-19 pandemic and associated constraints, we collected data at two different time points. The pre-pandemic data collection was conducted to analyze the general view of students on the digitalization of their HEIs (Brink, Packmohr, \& Vogelsang, 2020). An intra-pandemic data collection was added with the same instrument in the same courses to compare results. Thus, the respondents changed because we surveyed different cohorts of students. Nevertheless, the two groups follow the same study plans and have the same profiles.

The questionnaire comprises 16 different statements that refer to various potential areas of concern in digitalization. The students rated statements on a five-point Likert scale ranging from "I do not agree at all" (1) to "I strongly agree" (5).

The pre-pandemic sample was surveyed during August/September 2019, consisting of students from elective management courses: a) Business Process Management and (b) Digital Transformation. The students were asked in class to fill out a paper-based questionnaire. Additionally, we contacted students from earlier terms of these courses and included former participants of the course "Project Management" (Master's in Management/Information Systems) to participate in an online survey. We selected these courses because they instruct with a blended-learning approach of digital components and a supplementary attendance part. Furthermore, they included digitalized administrative processes such as course subscriptions, exam registrations, and communication supported by technology. From this sample, we received 97 completed questionnaires.

The intra-pandemic sample was surveyed during February 2021 in the same courses. In total, we were able to collect 113 completed questionnaires that were filled out online. Due to the 
global Covid-19 pandemic, the course designs have massively changed due to contact restrictions and hygiene regulations. The courses went from a blended design to digitally only. Even the supplementary attendance part was conducted online. Besides, exams were taken online, and the administrative processes were converted into contactless and digital services. As a result, student life has taken place solely at home. Thus, students were likely to be confronted more with the issue of digitalization at their HEI.

Currently, the digitalization at HEIs is provoked through an externality. Comparing the preand intra-pandemic samples offers the chance to examine the change in students' perceptions.

\section{Results and Discussion}

In the following, the results from both time points are compared to understand the impact of the Covid-19 pandemic on students' attitudes in greater detail. We compare the means and standard deviations (std. dev.) of both samples' statements. Also, we calculate the deviation (delta) between these two time points to demonstrate the differences. Table 1 shows the results.

Regarding the pre-pandemic results, the mean values for the changed learning characteristic show no felt disadvantage from the blended learning design. However, the students do not emphasize a clear digital progression within the teaching by their HEI. Results from the intrapandemic sample look much differently. The students see more disadvantages in their learning with the online courses. Also, the digital progression is judged more critically. This characteristic shows the highest deltas of the study. Even the std. dev. shows higher results. The students realize a small change in the digitalization of services. A greater change is registered within the digitalization of processes. The std. dev. raised a bit for the services. Thus, the opinions of the students have a greater variation. Students perceive a positive effect of enforced digitalization within the HEI's processes, e.g., making tasks such as registrations easier. Although students are more critical of the HEI's culture, they have a more positive perception than before towards constant development and new teaching ideas. Especially in this characteristic, there might be a clash between long-term and short-term effects. New teaching ideas, such as setting up break-out rooms for small group discussion, can be organized easily. Cultural changes take a longer time. Especially concerning fast-moving technologies, the culture at HEIs might be perceived as more and more traditional. The smallest changes are visible in the resources. At the same time, both means are rather high, showing a limiting factor in digitalization. Likewise, students do not perceive an increase in projects and positions related to digitalization. As digitalization became an imperative during the pandemic, HEIs are forced to adapt their strategies. Students recognize the efforts made during the pandemic. 
Table 1. Mean Values and Standard Deviation.

\begin{tabular}{|c|c|c|c|c|c|c|}
\hline \multirow[b]{2}{*}{ Characteristic } & \multirow{2}{*}{$\begin{array}{l}\text { Statements in keywords related } \\
\text { to students' HEI perception }\end{array}$} & \multicolumn{2}{|c|}{ Pre-Covid } & \multicolumn{2}{|c|}{ Intra-Covid } & \multirow{2}{*}{$\begin{array}{l}\text { Delta } \\
\text { Mean }\end{array}$} \\
\hline & & Mean & $\begin{array}{l}\text { Std. } \\
\text { Dev. }\end{array}$ & Mean & $\begin{array}{l}\text { Std. } \\
\text { Dev. }\end{array}$ & \\
\hline \multirow{4}{*}{$\begin{array}{l}\text { Changed } \\
\text { Learning }\end{array}$} & Changed course form harms & 1,05 & 1,05 & 3,31 & 1,29 & 2,26 \\
\hline & learning success & & & & & \\
\hline & $\begin{array}{l}\text { No advantages of technical support } \\
\text { by the digital learning platform }\end{array}$ & 1,87 & 1,02 & 2,84 & 1,13 & 0,97 \\
\hline & $\begin{array}{l}\text { Existing methods for teaching \& } \\
\text { services }\end{array}$ & 2,04 & 0,72 & 3,51 & 1,22 & 1,47 \\
\hline \multirow[t]{2}{*}{$\begin{array}{l}\text { Changed } \\
\text { Services }\end{array}$} & $\begin{array}{l}\text { Digital services offered to support } \\
\text { studies }\end{array}$ & 3,40 & 1,04 & 3,62 & 1,27 & 0,22 \\
\hline & Internal processes digitized & 2,92 & 1,07 & 3,77 & 1,04 & 0,85 \\
\hline Cultural & No change in learning culture & 2,10 & 1,02 & 3,03 & 1,30 & 0,93 \\
\hline \multirow[t]{2}{*}{ Change } & $\begin{array}{l}\text { Constant learning to get better in } \\
\text { how to transform digitally }\end{array}$ & 3,26 & 0,95 & 3,77 & 0,96 & 0,51 \\
\hline & Openness to new ideas in teaching & 3,36 & 1,01 & 3,85 & 1,06 & 0,49 \\
\hline \multirow[t]{2}{*}{ Resources } & $\begin{array}{l}\text { Specific jobs/projects for } \\
\text { digitalization }\end{array}$ & 3,29 & 0,79 & 3,44 & 0,89 & 0,15 \\
\hline & $\begin{array}{l}\text { Not enough resources for the digital } \\
\text { learning platform }\end{array}$ & 2,51 & 1,09 & 2,84 & 1,28 & 0,33 \\
\hline \multirow[t]{3}{*}{ Strategy } & HEI's digitalization moves forward & 3,33 & 0,94 & 3,87 & 1,02 & 0,54 \\
\hline & $\begin{array}{l}\text { Management supports digital } \\
\text { transformation }\end{array}$ & 3,25 & 0,83 & 3,92 & 1,09 & 0,67 \\
\hline & HEI has clear vision or DT strategy & 2,94 & 0,84 & 3,48 & 1,07 & 0,54 \\
\hline \multirow[t]{3}{*}{ Trust } & Own control of data storage & 2,55 & 1,16 & 3,18 & 1,04 & 0,63 \\
\hline & $\begin{array}{l}\text { Trust in HEI in handling generated } \\
\text { data }\end{array}$ & 3,86 & 0,99 & 3,41 & 1,24 & $-0,45$ \\
\hline & $\begin{array}{l}\text { No effect of data transparency on } \\
\text { digital learning platform use }\end{array}$ & 3,66 & 1,02 & 3,56 & 1,01 & $-0,1$ \\
\hline
\end{tabular}

Source: Cf. (Brink, Packmohr, \& Vogelsang, 2020) for exact wordings of the items.

The commitment of the HEI's management to digitalization is perceived more clearly. The last characteristic shows a further negative impact. Due to the Covid-19 pandemic, teaching is increasingly handled via digital learning platforms. Data from the platforms that lectures 
can access does not change the platform's use. Although, students show lower trust in the HEI in handling their data in general. Especially at the beginning of the pandemic, not every HEI could rely on privacy-compliant systems and had to use, e.g., video conferencing systems with questionable data protection.

Comparing the pre-pandemic and the intra-pandemic sample clearly shows a negative trend in the characteristic changed learning. Students emphasize that the changed form of the courses in the pandemic harms their learning success. The study's greatest delta $(2,26)$ is observed here. The standard deviation also increased for almost all statements, indicating that attitudes are more divergent among students. As a pandemic is a complex experience, it is not affecting all students equally. This effect was also demonstrated in a study by Aucejo et al. (2020). In particular, low-income students were more negatively affected. Although other studies found an improvement in students' performance during the pandemic (Gonzalez et al., 2020), the perceived learning success doesn't seem to indicate the same result. Generally, there seems to be despair between young people's perception and their real knowledge (Sommer 2014). In this case, students' performance might be better than they would expect it due to the changing environment.

\section{Conclusions and Limitations}

This study focuses on students' perception of higher education institutions' digitalization at different time points of the Covid-19 pandemic. We surveyed a group of management students in different courses with a blended (pre-pandemic) and complete online design (intra-pandemic).

Our results show that students' perceptions toward digitalization at HEIs differ in many aspects due to the pandemic. Students during the pandemic are much more critical of the HEIs' digitalization in terms of their own learning success. They perceive the blended course design as superior to the online design. However, the increasing standard deviation suggests that not all students are affected equally.

The pandemic had caused a need to change the course designs in a short time. Also, the HEI was forced to offer its services digitally immediately. For the students and all other stakeholders, this development was an exceptional change. Our study indicates that the adaptation has taken place more quickly in services and that teaching concept and the learning culture lag development. Adjusting to the new status quo takes time. Further monitoring is needed to evaluate how student attitudes change over time. Moving away from traditional teaching methods, such as transforming lectures to an online format, might require more lead time. Also, transforming the culture of learning is a long-term task. 
The research presented is not without limitations. The results are based on a survey of management students in some of their elective courses. This group could have a positive relationship to digitalization, leading to a bias. Furthermore, a longitudinal study of the same cohort of students can be expected to generate more reliable results as the perception of the same respondents would be collected over time. Unfortunately, it is hardly possible to control such a study as students fluctuate. The students surveyed show some affinity to technology. The courses they studied are electives loosely connected to the topic of Information Systems. Thus, we aim to further examine the topic in a larger survey with a more diversified group of students from other less and more technology affine programs and other levels of education. Also, an additional collection of demographic data, such as income or living situation, could lead to a better explanation of the higher std. devs. Generally, a pandemic is an extensive experience leading to stress in a lot of different aspects of life. In our study, students experience differences in the course design as a proxy for a pandemic experience. Thus, we do not directly measure the influence of the pandemic. Currently, a greater negativity regarding pandemic restrictions could have an impact on our results. A post-pandemic follow-up might lead to more clarification.

\section{References}

Adler, N. J., \& Harzing, A.-W. (2017). When Knowledge Wins: Transcending the Sense and Nonsense of Academic Rankings. Academy of Management Learning \& Education, 8, 72-95.

Al-Senaidi, S., Lin, L., \& Poirot, J. (2009). Barriers to adopting technology for teaching and learning in Oman. Computers \& Education, 53, 575-590.

Aucejo, E. M., French, J., Ugalde Araya, M. P., \& Zafar, B. (2020). The impact of COVID19 on student experiences and expectations: Evidence from a survey. Journal of Public Economics, 191, 104271.

Brink, H., Packmohr, S., \& Vogelsang, K. (2020). The digitalization of universities from a students' perspective. 6th International Conference on Higher Education Advances (HEAd'20), 967-974.

Carver, L. B. (2016). Teacher Perception of Barriers and Benefits in K-12 Technology Usage. Turkish Online Journal of Educational Technology - TOJET, 15, 110-116.

Castro, R. (2019). Blended learning in higher education: Trends and capabilities. Education and Information Technologies, 24, 2523-2546.

Crittenden, W. F., Biel, I. K., \& Lovely, W. A. (2019). Embracing Digitalization: Student Learning and New Technologies. Journal of Marketing Education, 41, 5-14.

Friga, P. N., Bettis, R. A., \& Sullivan, R. S. (2003). Changes in Graduate Management Education and New Business School Strategies for the 21st Century. Academy of Management Learning \& Education, 2, 233-249. 
Gonzalez, T., de la Rubia, M. A., Hincz, K. P., Comas-Lopez, M., Subirats, L., Fort, S., \& Sacha, G. M. (2020). Influence of COVID-19 confinement on students' performance in higher education. PLOS ONE, 15, e0239490.

Gregory, M. S.-J., \& Lodge, J. M. (2015). Academic workload: The silent barrier to the implementation of technology-enhanced learning strategies in higher education. Distance Education, 36, 210-230.

Janson, A., Söllner, M., Bitzer, P., \& Leimeister, J. M. (2014). Examining the effect of different measurements of learning success in technology-mediated learning research. 35th International Conference on Information Systems (ICIS), 1-10.

Lapitan, L. DS., Tiangco, C. E., Sumalinog, D. A. G., Sabarillo, N. S., \& Diaz, J. M. (2021). An effective blended online teaching and learning strategy during the COVID-19 pandemic. Education for Chemical Engineers, 35, 116-131.

Miller, M. T. (2021). Do learning organizations learn? Higher education institutions and pandemic response strategies. The Learning Organization, 28.

Mittal, A., Mantri, A., Tandon, U., \& Dwivedi, Y. K. (2021). A unified perspective on the adoption of online teaching in higher education during the COVID-19 pandemic. Information Discovery and Delivery, 49.

Ouajdouni, A., Chafik, K., \& Boubker, O. (2021). Measuring e-learning systems success: Data from students of higher education institutions in Morocco. Data in Brief, 35, 106807.

Porter, W. W., \& Graham, C. R. (2016). Institutional drivers and barriers to faculty adoption of blended learning in higher education: Drivers and barriers to blended learning adoption. British Journal of Educational Technology, 47, 748-762.

Proserpio, L., \& Gioia, D. A. (2007). Teaching the Virtual Generation. Academy of Management Learning \& Education, 6, 69-80.

Reid, P. (2014). Categories for barriers to adoption of instructional technologies. Education and Information Technologies, 19, 383-407.

Talley, C. P., \& Scherer, S. (2013). The Enhanced Flipped Classroom: Increasing Academic Performance with Student-recorded Lectures and Practice Testing in a "Flipped" STEM Course. Journal of Negro Education, 82, 339-347, 357. Social Science Premium Collection (1531932257; 201424909).

Tejedor, S., Cervi, L., Pérez-Escoda, A., Tusa, F., \& Parola, A. (2021). Higher Education Response in the Time of Coronavirus: Perceptions of Teachers and Students, and Open Innovation. Journal of Open Innovation: Technology, Market, and Complexity, 7, 43.

Tselios, N. K., Daskalakis, S., \& Papadopoulou, M. (2011). Assessing the Acceptance of a Blended Learning University Course. Educational Technology \& Society, 14, 224-235.

Vogelsang, K., Droit, A., \& Liere-Netheler, K. (2019). Designing a Flipped Classroom Course-a Process Model. Proceedings of the 14th International Conference on Wirtschaftsinformatik, 345-359. 